\title{
Metodologías y perspectivas para el análisis de la evolución de la profesión y la investigación en información y documentación
}

\author{
Francisco Javier García Marco \\ Universidad de Zaragoza (España)
}

\section{Resumen}

Se presentan los artículos que componen el número 2 del volumen 12 de la revista Scire: Organización y Representación del Conocimiento (jul.-dic. 2006), dedicado fundamentalmente al análisis de la evolución de las profesiones, la enseñanza y la investigación en ciencia de la información.

Palabras clave: Ciencias de la documentación. Profesional de la información. Investigación. Evolución. Tendencias. Perspectivas.

\begin{abstract}
The articles published in the number 2 of the volume 12 of Scire (Jul.-Dec. 2006) are presented, which are mainly devoted to the evolution of profession, education and scientific research in information science.
\end{abstract}

Key words: Information science. Information professional. Evolution. Research. Trends. Perspectives.

\section{Introducción}

Este segundo número del volumen 12 de la revista Scire: Organización y Representación del Conocimiento (jul.-dic. 2006) presenta perspectivas, metodologías y evidencias sobre aspectos cruciales de la intensa evolución — ¿revolución?que está sufriendo el mundo de la información y la documentación en sus tres dimensiones — el ejercicio profesional, la formación y la educación-y la investigación en sus aspectos profesionales, como, lógicamente, en los relacionados con la investigación en ciencia de la información.

\section{Los cambios en la profesión y en la docencia}

El artículo de Cunha y Crivellari (2006) aborda el problema del desenfoque que se da actualmente en la enseñanza y la práctica profesional de las ciencias de la documentación. Se constata que, a pesar de las fluctuaciones en el enfoque que se están 
produciendo en el nombre de la profesión y los programas de estudio, el 90\% del empleo en Brasil se mantiene en las bibliotecas, archivos y museos, "con diversificación cualitativa, en otros sectores, pero no cuantitativa". No se ha producido una migración del trabajo hacia los sectores .com como en un momento se esperaba, lo que pone en cuestión muchas reflexiones y esperanzas de mitad de la década de los noventa. Esta constatación sobre el empleo real de los titulados en información y documentación se contrasta en el artículo siguiente de Cunha (2006) con un análisis de las ofertas de trabajo presentadas por los empleadores entre enero de 2005 y junio de 2006. El profesional tipo resulta también ser un bibliotecario con formación superior y con experiencia informática para trabajar en la ciudad de São Paulo, aunque los empleadores fluctúan en la especificación del perfil profesional que desean. Para Cunha, esto último es un síntoma de la "mutación de los espacios de trabajo", todavía incipiente en Brasil. No podemos sino manifestar nuestro acuerdo con su análisis, en la línea de lo que está pasando sobre todo en Estados Unidos.

En esta dirección se entienden las propuestas estratégicas para la docencia en el área de Rodrigues (2006), que también concuerdan con las del movimiento norteamericano de las iSchools:

Hoy, la formación profesional en el área de la ciencia de la información no puede restringirse a la perspectiva de una profesionalización estricta, especializada. Además del dominio de los contenidos inherentes al área, el profesional debe estar preparado para afrontar con competencia y creatividad los problemas derivados de su práctica profesional, así como para producir y difundir conocimientos y para reflejar críticamente la realidad que lo rodea. Por ello se pone de manifiesto la necesidad de una enseñanza dinámica, con docentes que utilicen tecnologías de información y comunicación, que no trabajen de forma aislada, sino en redes académicas nacionales e internacionales, que dominen el conocimiento contemporáneo y lo usen para la resolución de problemas.

Por fin, el trabajo de Prat (2006) sirve para ejemplificar y concretar un proyecto educativo apoyado fundamentalmente en las nuevas tecnologías para la formación en línea en gestión de la información digital en los medios de comunicación.

\section{Cuantificando la investigación en ciencia de la información}

Este número contiene también un interesantísimo panel de estudios sobre las metodologías de la investigación que comparten un enfoque más cuantitativo y cercano a la ciencia social. Así, Setién (2006) encabeza la serie con "Una llamada de alerta ante algunos de los denominados enfoques cualitativos en las investigaciones bibliotecológicas".

Este autor revindica la objetividad —en el sentido de un espacio sólido para la discusión honesta- que proporciona una cuantificación bien hecha. En el otro 
brazo de la balanza, López Yepes y Salvador (2006) revindican el "análisis cuantitativo de citas" como metodología imprescindible para complementar el análisis cuantitativo, y lo hacen a través de un estudio concreto sobre la visibilidad del Departamento de Biblioteconomía y Documentación de la Universidad Complutense de Madrid (1984-2003). Ciertamente, el análisis cuantitativo solo es útil si se realiza a partir de un riguroso análisis cualitativo en el que se identifican las entidades y relaciones a cuantificar.

Perianes, Olmeda y Ovalle (2006) se plantean el reto de conceptualizar con mayor precisión en qué manera la medida de la productividad científica y la de su impacto se relacionan con el concepto de excelencia, el objetivo último de la actividad científica.

Siguen tres valiosos estudios de caso muy interesantes que abordan el análisis de una revista de ciencia de la información (Silva, Pinheiro y Menezes, 2006), el de la producción científica de un centro de investigación, el Instituto Nacional de Técnica Aerospacial (Paz, Alonso y Mérida, 2006), y un tema de enorme relevancia en la actualidad: el agua y su gestión (Fernández, Jiménez y Salvador, 2006).

\section{Desarrollando recursos}

En la dirección de desarrollar recursos de información, tan importantes en la investigación aplicada y teórica de nuestra área, se insertan los trabajos de Gómez y García (2006) para el desarrollo del Nuevo diccionario de archivística —innovador tanto por su abordaje de los nuevos tópicos, especialmente los relacionados con los documentos electrónicos, como por su metodología, rigurosamente apoyada en la lexicografía contemporánea—, y Torregrosa y Sánchez (2006) en la creación de una base de datos de recursos electrónicos para la documentación informativa, especialmente en los campos de prensa, medios audiovisuales y publicidad.

\section{Referencias}

Cunha, Miriam Vieira da (2006). Espacios de trabajo para profesionales de la información en Brasil: resultados preliminares. // Scire: Representación y Organización del Conocimiento. 12:2 (jul.-dic. 2006) 27-36.

Cunha, Miriam Vieira da; Crivellari, Helena Maria Tarchi (2006). Paradojas de las profesiones de la información en la sociedad del conocimiento. // Scire: Representación y Organización del Conocimiento. 12:2 (jul.-dic. 2006) 13-26.

Fernández Sánchez, Elena; Jiménez Hidalgo, Sonia; Salvador Bruna, Javier (2006). La sequía en España: análisis del fenómeno a través del estudio de las noticias de prensa recogidas por Hispagua durante el año 2005. // Scire: Representación y Organización del Conocimiento. 12:2 (jul.-dic. 2006) 137-150.

Gómez Díaz, Raquel; García Palacios, Joaquín (2006). Los documentos electrónicos de archivo: pautas para la realización del Nuevo diccionario de archivística. // Scire: Representación y Organización del Conocimiento. 12:2 (jul.-dic. 2006) 151-164.

Scire. $12: 2$ (jul.-dic. 2006) 9-12. ISSN 1135-3716. 
López Yepes, José; Salvador Bruna, Javier (2006). Análisis cuantitativo de citas: visibilidad del Departamento de Biblioteconomía y Documentación de la Universidad Complutense de Madrid (1984-2003). // Scire: Representación y Organización del Conocimiento. 12:2 (jul.-dic. 2006) 75-85.

Paz Otero, Silvia; Alonso Valdivieso, Miguel Ángel; Mérida Martín, Fernando (2006). Evolución de la producción científica del Instituto Nacional de Técnica Aerospacial (19902005). // Scire: Representación y Organización del Conocimiento. 12:2 (jul.-dic. 2006) 119-135.

Perianes Rodríguez, Antonio; Olmeda Gómez, Carlos; Ovalle Perandones, María Antonia (2006). Medir y evaluar la excelencia de la investigación científica: retos y soluciones. // Scire: Representación y Organización del Conocimiento. 12:2 (jul.-dic. 2006) 87-98.

Prat Sedeño, Judith (2006). Herramientas y estrategias de aprendizaje en línea para la formación de posgrado en gestión de la información digital en los medios de comunicación. // Scire: Representación y Organización del Conocimiento. 12:2 (jul.-dic. 2006) 55-67.

Rodrigues, Mara Eliane Fonseca (2006). Ciencia de la información y educación: la formación de los profesores de los profesionales de la información. // Scire: Representación y Organización del Conocimiento. 12:2 (jul.-dic. 2006) 37-53.

Setién Quesada, Emilio (2006). Una llamada de alerta ante algunos de los denominados enfoques cualitativos en las investigaciones bibliotecológicas. // Scire: Representación y Organización del Conocimiento. 12:2 (jul.-dic. 2006) 69-73.

Silva, Edna Lúcia da; Pinheiro, Liliane Vieira; Menezes, Estera Muszkat (2006). Encontros Bibli: Revista Eletrônica de Biblioteconomia e Ciência da Informação: análisis y evolución. // Scire: Representación y Organización del Conocimiento. 12:2 (jul.-dic. 2006) 99-117.

Torregrosa Carmona, Juan Francisco; Sánchez Hernández, María F. (2006). Recursos electrónicos para la documentación informativa: prensa, audiovisual y publicidad. // Scire: Representación y Organización del Conocimiento. 12:2 (jul.-dic. 2006) 165-175.

Scire. 12 : 2 (jul.-dic. 2006) 9-12. ISSN 1135-3716. 